\title{
Dynamic modelling of a combined cycle power plant with ThermoSysPro
}

\author{
Baligh El Hefni \\ Daniel Bouskela \\ Grégory Lebreton \\ EDF R\&D \\ 6 quai Watier, 78401 Chatou Cedex, France \\ baligh.el-hefni@edf.fr daniel.bouskela@edf.fr gregory.lebreton@edf.fr
}

\begin{abstract}
A new open source Modelica library called "ThermoSysPro" has been developed within the framework of the ITEA 2 EUROSYSLIB project. This library has been mainly designed for the static and dynamic modeling of power plants, but can also be used for other energy systems such as industrial processes, buildings, etc.

To that end, the library contains over 100 0D/1D model components such as heat exchangers, steam and gas turbines, compressors, pumps, drums, tanks, volumes, valves, pipes, furnaces, combustion chambers, etc. In particular, one and two-phase water/steam flow, as well as flue gases flow are handled.

The library has been validated against several testcases belonging to all the main domains of power plant modeling, namely the nuclear, thermal, biomass and solar domains.

The paper describes first the structure library. Then the test-case belonging to the thermal domain is presented. It is the dynamic model of a combined cycle power plant, whose objective is to study a step variation load from $100 \%$ to $50 \%$ and a full gas turbine trip. The structure of the model, the parameterization data, the results of simulation runs and the difficulties encountered are presented.
\end{abstract}

Keywords: Modelica; thermal-hydraulics; combined cycle power plant; dynamic modeling; inverse problems

\section{Introduction}

Modelling and simulation play a key role in the design phase and performance optimization of complex energy processes. It is also expected that they will play a significant role in the future for power plant maintenance and operation. Regarding for instance plant maintenance, a new method has been devel- oped to assess the performance degradation of steam generators because of tube support plate clogging, without having to wait for the yearly plant outage to open the steam generators for visual inspection [1]. The potential of Modelica as a means to efficiently describe thermodynamic models has been recognised for quite a while $[2,3]$ and lead to the initiative of developing a library for power plant modeling within the ITEA 2 EUROSYSLIB project.

This library is aimed at providing the most frequently used model components for the 0D-1D static and dynamic modelling of thermodynamic systems, mainly for power plants, but also for other types of energy systems such as industrial processes, energy conversion systems, buildings etc. It involves disciplines such as thermalhydraulics, combustion, neutronics and solar radiation.

The ambition of the library is to cover all the phases of the plant lifecycle, from basic design to plant operation. This includes for instance system sizing, verification and validation of the instrumentation and control system, system diagnostics and plant monitoring. To that end, the library will be linked in the future to systems engineering via the modeling of systems properties, and to the process measurements via data reconciliation.

Several test-cases were developed to validate the library in order to cover the full spectrum of usecases for power plant modeling:

- static and dynamic models of a biomass plant [8],

- dynamic model of a concentrated solar power plant,

- dynamic model of steam generators for sodium fast reactor [7],

- dynamic model of a 1300 MWe nuclear power plant covering the primary and secondary loops,

- dynamic model of a combined cycle power plant.

This paper is an introduction to ThermoSysPro library, and presents the combined cycle power plant test-case. 
Using dynamic models for combined cycle power plants (as well as for any other type of power plants) allows to go beyond the study of fixed set points to:

- check precisely the performances and the design given by the manufacturers (commissioning),

- verify and validate by simulation the scenario of large transients such as gas turbine trips,

- find optimised operating points,

- find optimised operation procedures,

- perform local and remote plant monitoring,

- build correction curves,

- etc.

In order to challenge the dynamic simulation capabilities of the library, a step load variation from $100 \%$ to $50 \%$ and a turbine trip (sudden stopping of the gas turbine) were simulated.

\section{Introduction to ThermoSysPro}

\subsection{Objectives of the library}

From the end-user's viewpoint, the objectives of the library are:

- Ability to model and simulate thermodynamic processes.

- Ability to cover the whole lifecycle of power plants, from basic design to plant operation and maintenance. This implies the ability to model detailed subsystems of the plant, and to model the whole thermodynamic cycle of the plant, including the I\&C system.

- Ability to initialize the models for a given operating point. This is essentially an inverse problem: how to find the physical state of the system given the values of the observable outputs of the system.

- Ability to perform static calculations (for plant monitoring and plant performance assessment) and dynamic calculations (for operation assistance) faster than real time.

- Ability to fit the plant models against real plant data using for instance data assimilation techniques.

- Ability to use the models to improve the quality of measurements using the data reconciliation technique.

- Ability to use the models for uncertainty studies by propagating uncertainties from the inputs to the outputs of the model.

From the model developer's viewpoint:

- The library should be easy to read, understand, extend, modify and validate.

- The library should be sharable at the EDF level, and more.
The library should be truly tool independent.

The library should be stable across language and tools versions.

The library should be validated against significant real applications.

The library should be fully documented. In particular, all modeling choices should be clearly justified.

\subsection{General principles of the library}

The library features multi-domain modeling such as thermal-hydraulics (water/steam, flue-gases and some refrigerants), neutronics, combustion, solar radiation, instrumentation and control.

The library is founded on first physical principles: mass, energy, and momentum conservation equations, up-to-date pressure losses and heat exchange correlations, and validated fluid properties functions. The correlations account for the non-linear behaviour of the phenomena of interest. They cover all water/steam phases and all flue gas compositions. Some components such as the multifunctional heater contains correlations that were obtained from experimental results or CFD codes developed by EDF. An early Modelica implementation of the IAPWS-IF97 standard by $\mathrm{H}$. Tummescheit is used for the computation of the properties of water and steam.

The level of modelling detail may be freely chosen. Default correlations are given corresponding to the most frequent use-cases, but they can be freely modified by the user. This includes the choice of the pressure drop or heat transfer correlations. Special attention is given to the handling of two-phase flow, as two-phase flow is a common phenomenon in power plants. The physics of two-phase flow is complex because of the mass and energy transfer between the two phases and the different flow regimes (bubbles, churn or stratified flow...) [4]. Currently, mixed and two-fluids 3, 4 and 5 equations flow models are supported. For instance, 3 equations are used for the homogeneous single-phase flow pipe model, 4 equations for the drum model, and 5 equations for the separated flow pipe model. The different flow regimes are accounted for by appropriate pressure drop and heat transfer correlations. The drift-flux model may be used to compute the phase velocities. Also, accurate sets of geometrical data are provided for some heat exchangers.

Flow reversal is supported in the approximation of convective flow only (the so-called upwind scheme where the Peclet number is supposed to be infinite [5]). It is planned to investigate the interest of taking diffusion into account for a more robust computation of flow reversal near zero-flow. 
ated by the connections, but fully implemented in the volumes, (2) and that the sign convention for positive flows is not compatible with the sign convention of the Modelica flow prefix, which stipulates that all flows should be of the same sign (positive or negative) when entering the component via the connector. As a consequence, multiple connections are not allowed as in Modelica.Fluid for instance, so that mergers or splitters must be modeled using volumes. In practice, this is not considered as a restriction, as in most cases, mergers or splitters do have non trivial physical behaviours which could not be simply represented by multiple connections.

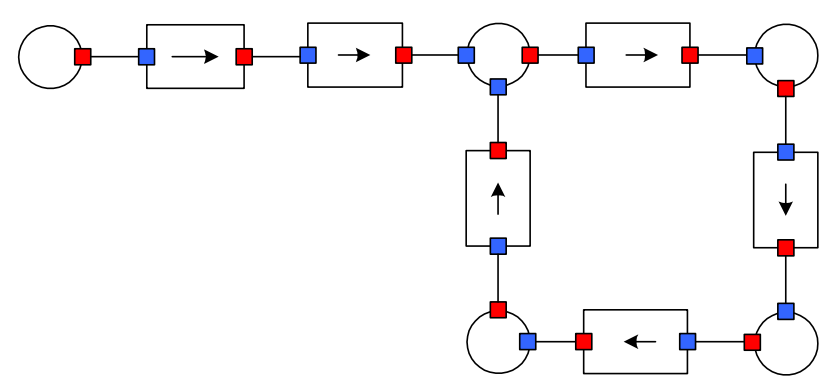

Figure 1: connecting components

$\mathrm{P}$ and $\mathrm{h}$ denote resp. the average fluid pressure and specific enthalpy inside the control volumes. $m_{-}$flow and $h$ flow denote resp. the mass flow rate and specific enthalpy crossing the boundary between two control volumes (see Figure 2).

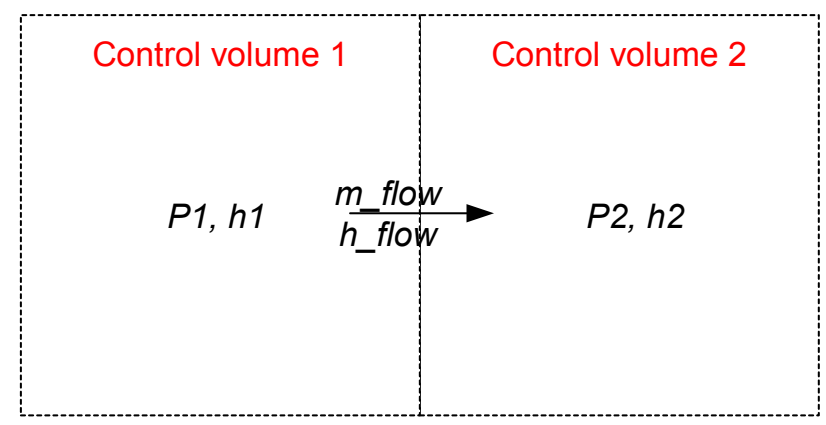

Figure 2: finite volume discretization

$\mathrm{P}, \mathrm{h}$ and $\mathrm{m}$-flow are the state variables of resp. the mass, energy and balance equations. $h$ flow is not a state variable. The purpose of $h$ flow is to compute the fluid specific enthalpy using the upwind scheme. $\mathrm{P}$ and $\mathrm{h}$ are computed within volumes, whereas $\mathrm{m}$-flow and $\mathrm{h}$-flow are computed within flow models (see Figure 3).

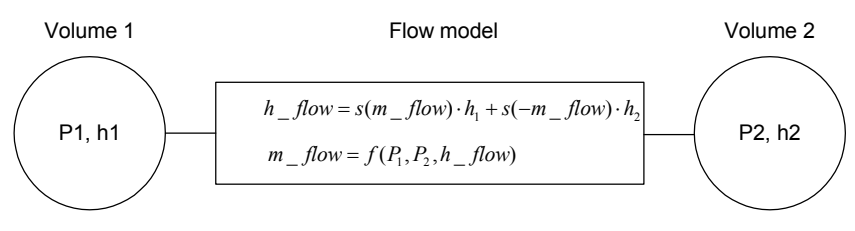

Figure 3: staggered grid scheme

According to the upwind scheme:

$$
h_{-} \text {flow }=s\left(m_{-} \text {flow }\right) \cdot h_{1}+s\left(-m_{-} \text {flow }\right) \cdot h_{2}
$$

where $s$ denotes the step function:

$$
s(x)=0 \text { if } x \leq 0 \text { and } s(x)=1 \text { if } x>0
$$

\subsection{Organization of the library}

The library is subdivided into application domains. Each application domain corresponds to a connector type. Each application domain is divided into packages corresponding to broad component types: boundary conditions, connectors, heat exchangers, machines, pressure losses, sensors, volumes, etc. (see Figure 5 in the Appendix).

Components may be written in plain Modelica text, or constructed by connecting other components from the library, as shown in Figure 4.

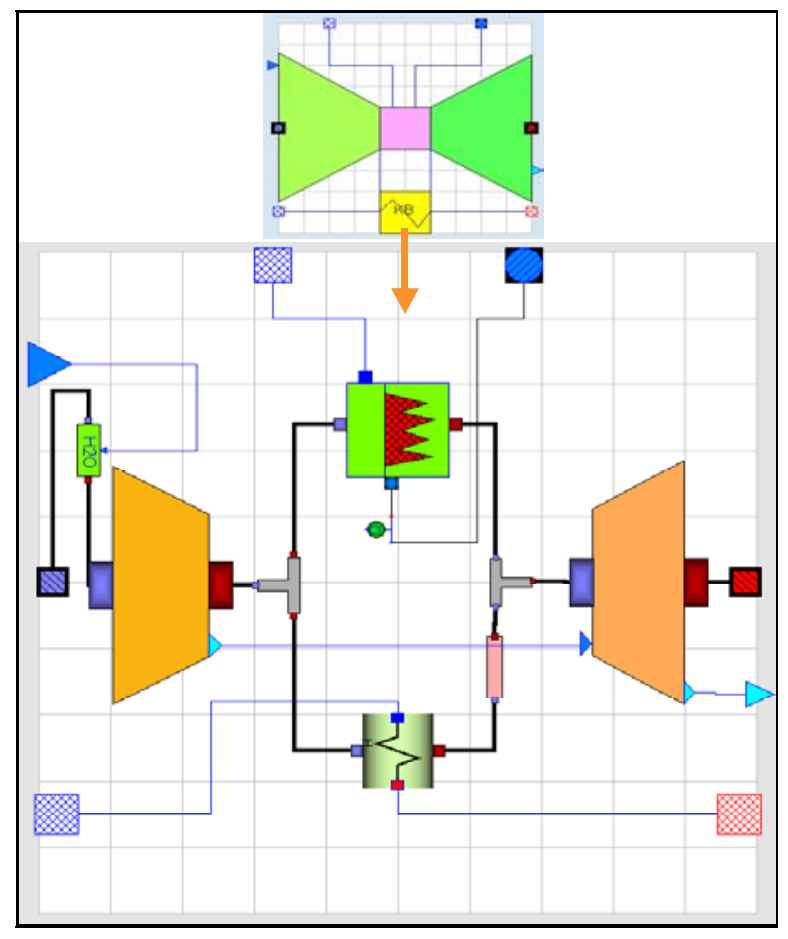

Figure 4: model component of a gas turbine 


\section{Model of the combined cycle power plant}

\subsection{Description of the model}

Actually, two models are used: one to simulate the power generator step reduction load (see Figure 6 in the Appendix), the other to simulate the full GT trip (see Figure 7 in the Appendix). In the model used to simulate the GT trip, the gas turbine is replaced by a boundary condition.

The model contains two main parts: the water/steam cycle and the flue gases subsystem. Only one train is modelled, so identical behaviour is assumed for each HRSG and for each gas turbine.

\section{HRSG model}

The model consists of 16 heat exchangers ( 3 evaporators, 6 economizers, 7 super-heaters), 3 evaporating loops (low, intermediate and high pressure), 3 drums, 3 steam turbine stages (HP, IP and LP), 3 pumps, 9 valves, several pressure drops, several mixers, several collectors, 1 condenser, 1 generator, several sensors, sources, sinks and the control system limited to the drums level control.

An important feature of this model is that the thermodynamic cycle is completely closed through the condenser. This is something difficult to achieve, because of the difficulty of finding the numerical balance of large closed loops.

The list of component used for the development of the HRSG model is given in Table 1.

Table 1: library components used in the HRSG model

\begin{tabular}{|l|l|}
\hline \multicolumn{1}{|c|}{ Type } & \multicolumn{1}{c|}{ Model name in the library } \\
\hline Condenser & DynamicCondenser \\
\hline Drum & DynamicDrum \\
\hline Generator & generator \\
\hline $\begin{array}{l}\text { Heat ex- } \\
\text { changer }\end{array}$ & $\begin{array}{l}\text { DynamicExchangerWaterSteamFlueGases } \\
= \\
\text { DynamicTwoPhaseFlowPipe } \\
\text { ExchangerFlueGasesMetal } \\
\text { HeatExchangerWall }\end{array}$ \\
\hline Pipe & LumpedStraightPipe \\
\hline Pump & StaticCentrifugalPump \\
\hline Sensor & SensorQ \\
\hline $\begin{array}{l}\text { Steam tur- } \\
\text { bine }\end{array}$ & StodolaTurbine \\
\hline Valve & ControlValve \\
\hline Water mixer & VolumeB, VolumeC \\
\hline
\end{tabular}

\begin{tabular}{|l|l|}
\hline \multicolumn{1}{|c|}{ Type } & \multicolumn{1}{c|}{ Model name in the library } \\
\hline $\begin{array}{l}\text { Water split- } \\
\text { ter }\end{array}$ & VolumeA, VolumeD \\
\hline
\end{tabular}

\section{Heat Exchanger : Flue Gases/Water Steam}

Based on first principles mass, momentum and energy balance equations, the following phenomena are represented:

- transverse heat transfer,

- mass accumulation,

- thermal inertia,

- gravity,

- pressure drop within local flow rate.

\section{Drum and Condenser}

Based on first principles mass and energy balance equations for water and steam, the following phenomena are represented:

- drum level and swell and shrink phenomenon,

- heat exchange between the steam/water and the wall,

- heat exchange between the outside wall and the external medium.

\section{Steam turbine}

Based on an ellipse law and an isentropic efficiency.

\section{Pump}

Based on the characteristics curves.

\section{Pressure drop in pipes}

Proportional to the dynamic pressure \pm the static pressure.

\section{Mixer/splitter}

Based on the mass and energy balances for the fluid.

\section{GT model}

The model consists of 1 compressor, 1 gas turbine, 1 combustion chamber, sources, sinks and 1 air humidity model.

The list of component models used for the development of the GT model is given in Table 2.

Table 2: library components used in the GT model

\begin{tabular}{|l|l|}
\hline \multicolumn{1}{|c|}{ Type } & \multicolumn{1}{c|}{ Model name in the library } \\
\hline Air humidity & AirHumidity \\
\hline Compressor & GTCompressor \\
\hline Gas turbine & CombutionTurbine \\
\hline $\begin{array}{l}\text { Combustion } \\
\text { chamber }\end{array}$ & GTCombustionChamber \\
\hline
\end{tabular}

\section{Gas turbine}

Based on correlations for the characteristic. 


\section{Compressor}

Based on correlations for the characteristic.

\section{Combustion chamber}

Based on first principles mass, momentum and energy balance equations. The pressure loss in the combustion chamber is taken into account.

\subsection{Data implemented in the model}

All geometrical data were provided to the model (pipes and exchangers lengths and diameters, heat transfer surfaces of exchangers, volumes...).

The plant characteristics are given below.

\section{Gas Turbine (GT)}

Compressor compression rate: 14

\section{Steam Generator (HRSG)}

HRSG with 3 levels of pressure.

High pressure circuit at nominal power: 128 bar

Intermediate pressure circuit at nominal power: 27 bar

Low pressure circuit at nominal power : 5.7 bar

\section{Steam Turbine}

High pressure at nominal power : 124.5 bar, $815 \mathrm{~K}$ Intermediate pressure at nominal power : 25.5 bar, $801 \mathrm{~K}$

Low pressure at nominal power : 4.8 bar, $430 \mathrm{~K}$

\section{Condenser}

Steam flow rate: $194 \mathrm{~kg} / \mathrm{s}$

Water temperature at the inlet: $300 \mathrm{~K}$

\subsection{Calibration of the model}

The calibration phase consists in setting (blocking) the maximum number of thermodynamic variables to known measurement values (enthalpy, pressure) taken from on-site sensors for $100 \%$ load. This method ensures that all needed performance parameters, size characteristics and output data can be computed.

The main computed performance parameters are:

- the characteristics of the pumps,

- the ellipse law coefficients of the turbines,

- the isentropic efficiencies of the turbines,

- the friction pressure loss coefficients of the heat exchangers and of the pipeline between the equipments,

- the CV of the valves and the valves positions (openings).

\subsection{Simulation scenarios}

For simulation runs, two scenarios were selected.

The first scenario is a power generator step reduction from 100 to $50 \%$ load:

- Initial state (combined cycle): $100 \%$ load

- Final state (combined cycle): $50 \%$ load (800 s slope)

The second scenario is a full GT trip (sudden stopping of the gas turbine):

- Initial state (GT exhaust): $894 \mathrm{~K}, 607 \mathrm{~kg} / \mathrm{s}$

- Final state (GT exhaust): $423 \mathrm{~K}, 50 \mathrm{~kg} / \mathrm{s}(600 \mathrm{~s}$ slope)

The following phenomena are simulated:

- flow reversal,

- local boiling or condensation,

- swell and shrink effect in drums,

- drums levels and condenser level,

- drums pressure control

\subsection{Simulation scenarios}

Simulation runs were done using Dymola 6.1.

The simulation of the scenarios were mostly successful. However, some difficulties were encountered when simulating large transients, mainly stemming from the large size of the model:

- poor debugging facility,

- slow simulation,

- large number of values to be manually provided by the user for the iteration variables,

- no efficient handling of these values.

In particular, it has been observed that sometimes Dymola cannot calculate the initial states, even when all iterations variables are set very close to their solution values. This was the main difficulty that was encountered when closing the loop through the condenser.

When Dymola stops before the end of the simulation, no clear message is delivered to analyse the causes of the failure.

Tool improvements were analysed and reported as part of the EDF contribution to the EUROSYSLIB project, in partnership with Politecnico di Milano [6].

\subsection{Simulation results}

The model is able to compute precisely:

- the air excess,

- the distribution of water and steam mass flow rates,

- the thermal power of heat exchangers, 
- the electrical power provided by the generator,

- the pressure temperature and specific enthalpy distribution across the network,

- the drums levels and the condenser level,

- the performance parameters of all the equipments,

- the global efficiencies of the water/steam cycle and gas turbine.

The computational time is faster than real time (with Dymola 6.1).

The results of the simulation for $100 \%$ load are given below.

\section{Gas Turbine (GT)}

Nominal power: $2 * 230 \mathrm{MW}$,

\section{Steam Generator (HRSG)}

Thermal power: $2 * 350 \mathrm{MW}$,

\section{Steam Turbine}

Nominal power: $275 \mathrm{MW}$,

\section{Condenser}

Thermal power: $423 \mathrm{MW}$.

Outlet water temperature: $306 \mathrm{~K}$

Vacuum pressure: $6100 \mathrm{~Pa}$

The results of the simulation runs are given in Figure 8 and Figure 9 in the Appendix. They are consistent with the engineer's expertise.

However, when the GT trip reaches full stopping of the plant, the recirculation flows in the evaporators do not go to zero as expected, for reasons that are not yet fully understood.

\section{Conclusion}

A new open source Modelica library called 'ThermoSysPro' has been developed within the framework of the ITEA 2 EUROSYSLIB project. This library has been mainly designed for the static and dynamic modeling of power plants, but can also be used for other energy systems such as industrial processes, buildings, etc. It is intended to be easily understood and extendable by the models developer. Among other test-cases, a dynamic and rather large model of a combined cycle power plant has been developed to validate the library. This model comprises the flue gas side and the full thermodynamic water/steam cycle closed through the condenser. Two difficult transients were simulated: a step reduction load of the power generator and a full gas turbine trip. The results are mostly consistent with the engineer's expertise.
Despite of some simulation difficulties because of the lack of debugging tools for Modelica models, this work shows that the library is complete and robust enough for the modelling and simulation of complex power plants. However these two essential qualities for a power plant library should continuously be improved and maintained in the long run.

\section{Acknowledgements}

This work was partially supported by the panEuropean ITEA2 program and the French government through the EUROSYSLIB project.

\section{References}

[1] Bouskela D., Chip V., El Hefni B., Favennec J.M., Midou M. and Ninet J. 'New method to assess tube support plate clogging phenomena in steam generators of nuclear power plants', Mathematical and Computer Modelling of Dynamical Systems, 16: 3, 257-267, 2010.

[2] El Hefni B., Bouskela D., 'Modelling of a water/steam cycle of the combined cycle power plant "Rio Bravo 2" with Modelica', Modelica 2006 conference proceedings.

[3] Souyri A., Bouskela D., 'Pressurized Water Reactor Modelling with Modelica', Modelica 2006 conference proceedings.

[4] Collier J.G., and Thome J.R., 'Convective Boiling and Condensation', Mc Graw-Hill Book Company (UK) limited, 1972 Clarendon Press, Oxford, 1996.

[5] Patankar S.V., 'Numerical Heat Transfer and Fluid Flow', Hemisphere Publishing Corporation, Taylor \& Francis, 1980.

[6] Casella F., Bouskela D., 'Efficient method for power plant modelling', EDF report HP1C-2010-01929-EN, 2010.

[7] David F., Souyri A., Marchais G., 'Modelling Steam Generators for Sodium Fast Reactors with Modelica', Modelica 2009 conference proceedings

[8] El Hefni B., Péchiné B., 'Model driven optimization of biomass CHP plant design', Mathmod conference 2009, Vienna, Austria. 


\section{Appendix}

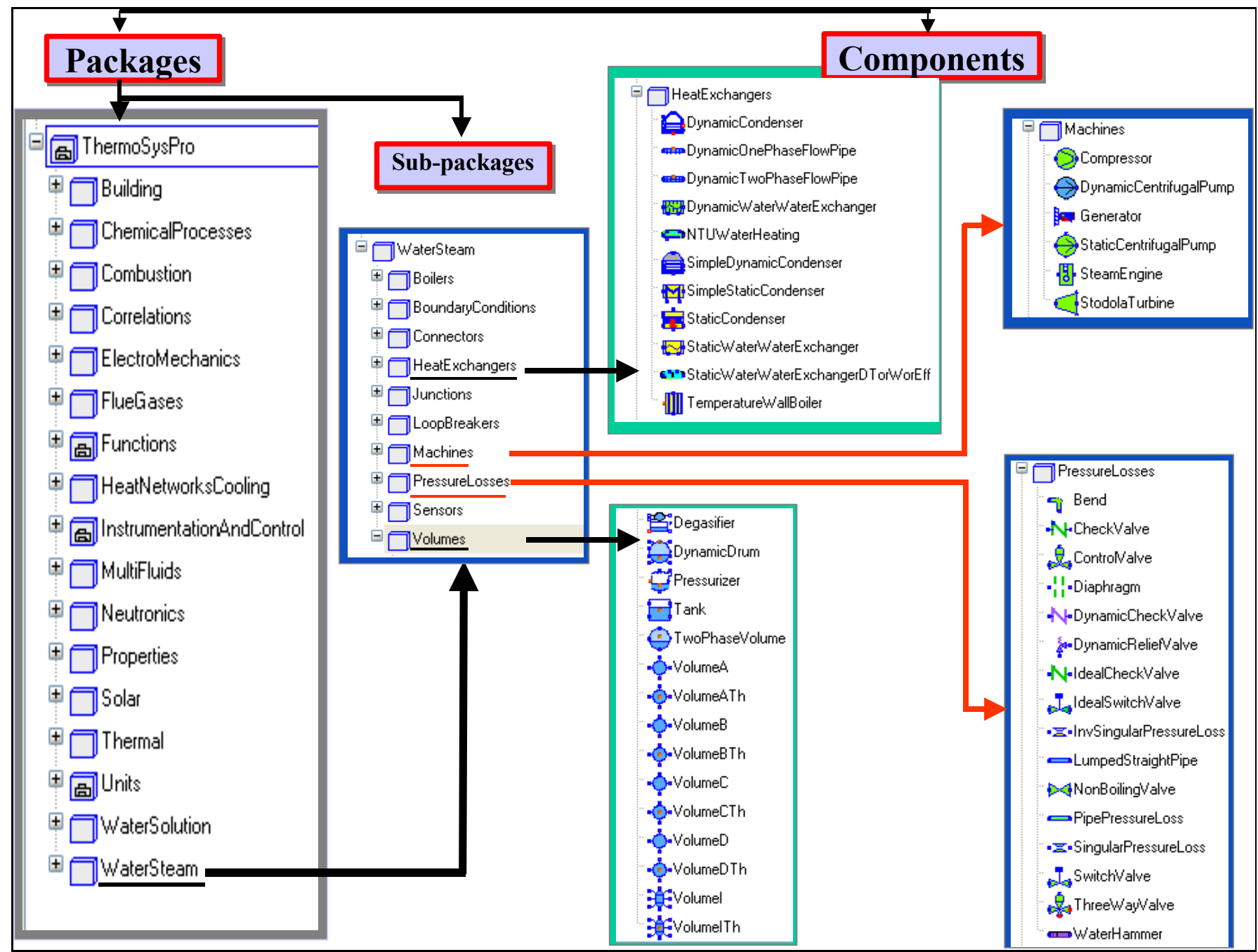

Figure 5: organization of the library 


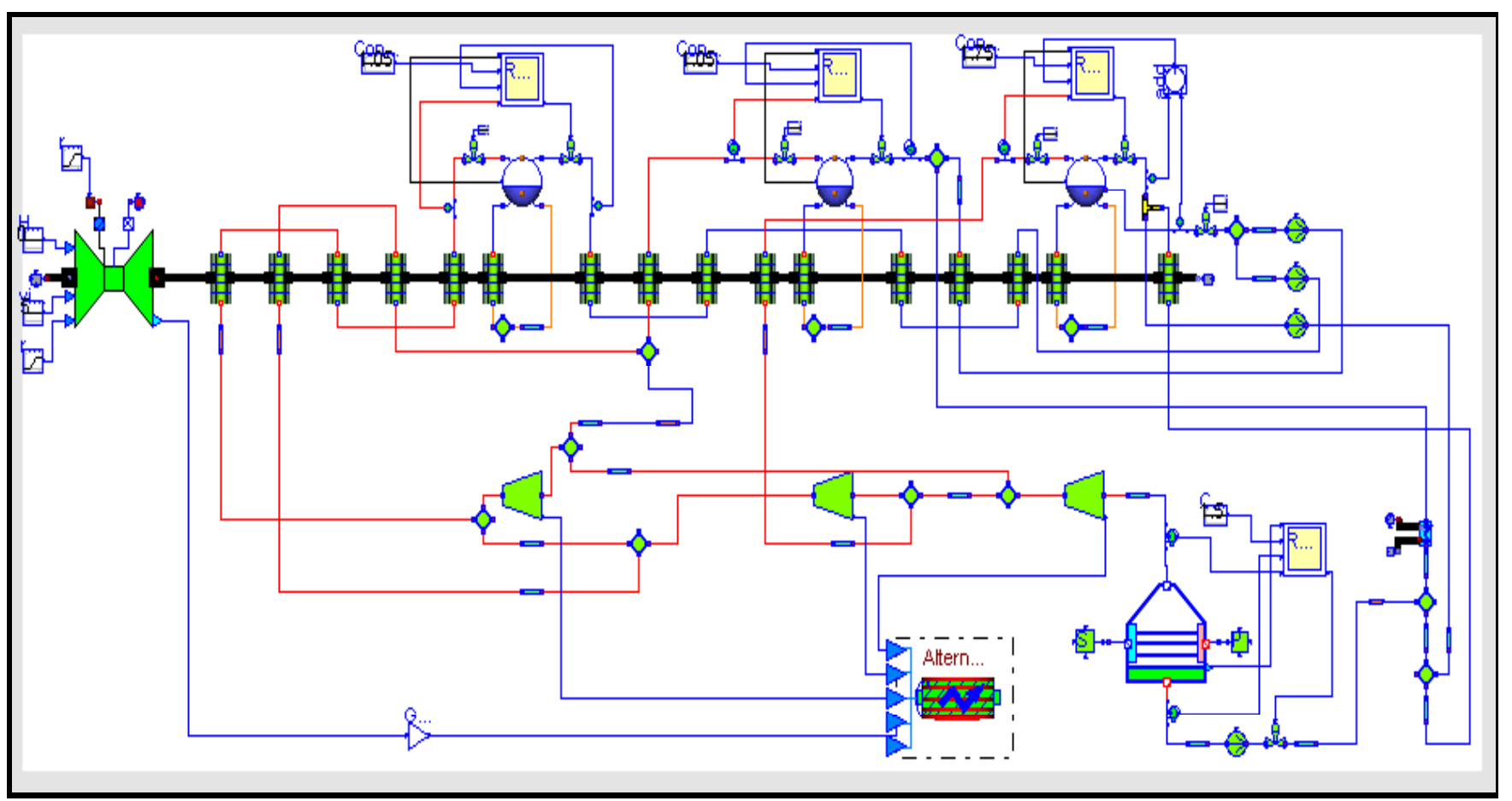

Figure 6: model of the combined cycle power plant used for the power generator step reduction load

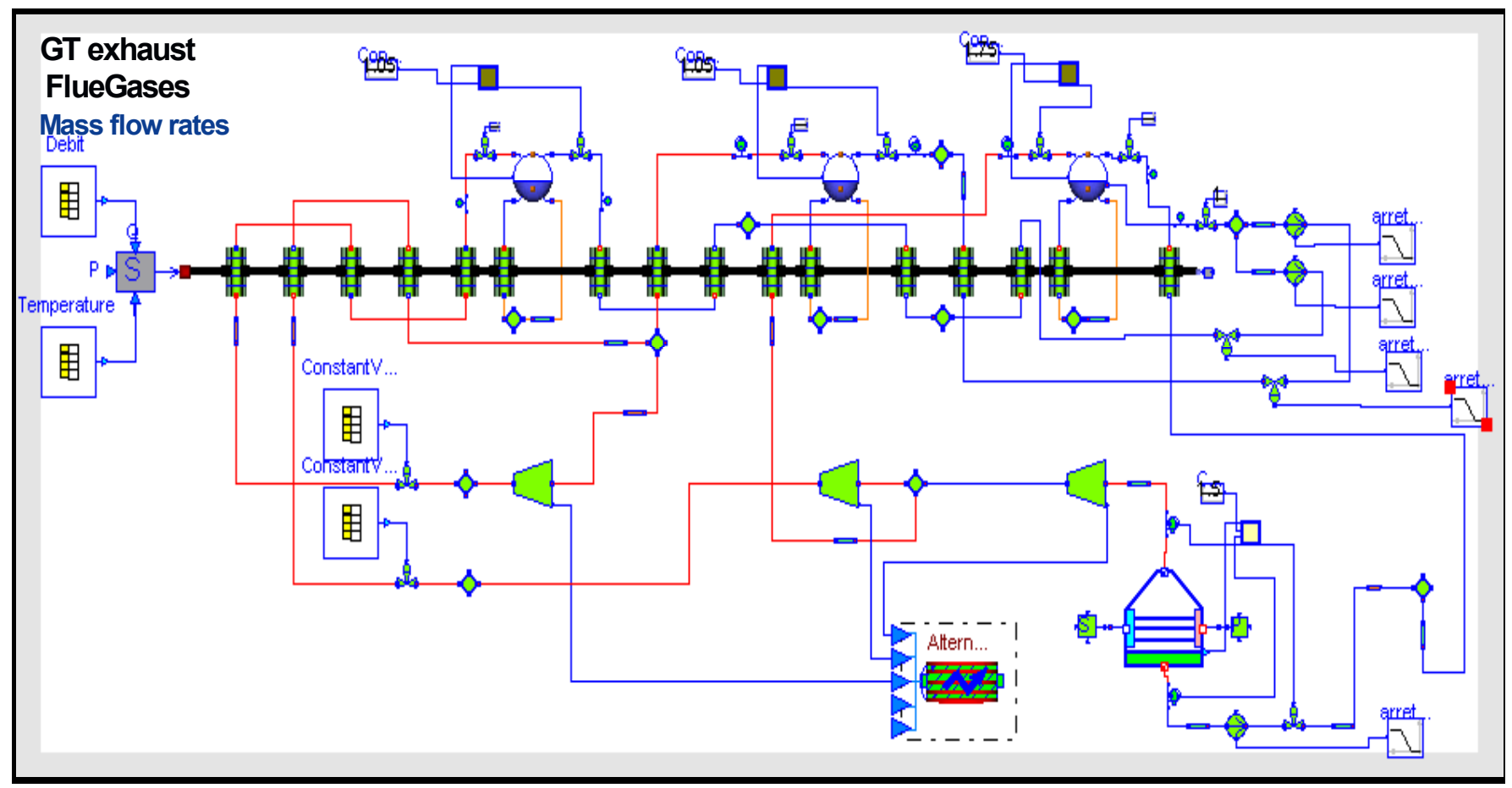

Figure 7: model of the combined cycle power plant used for the full GT trip 


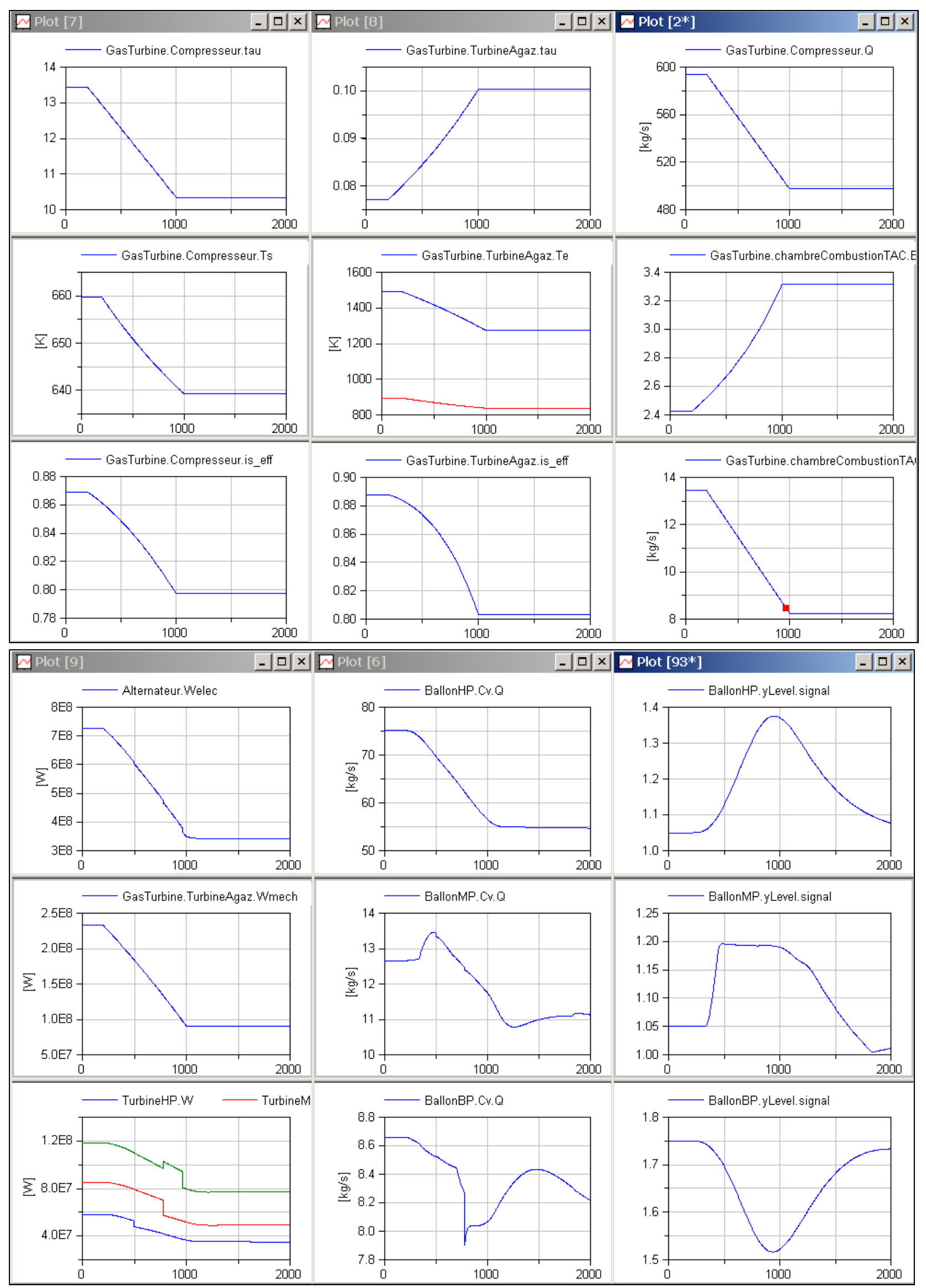

Figure 8: power generator step reduction simulation (-50\%) 


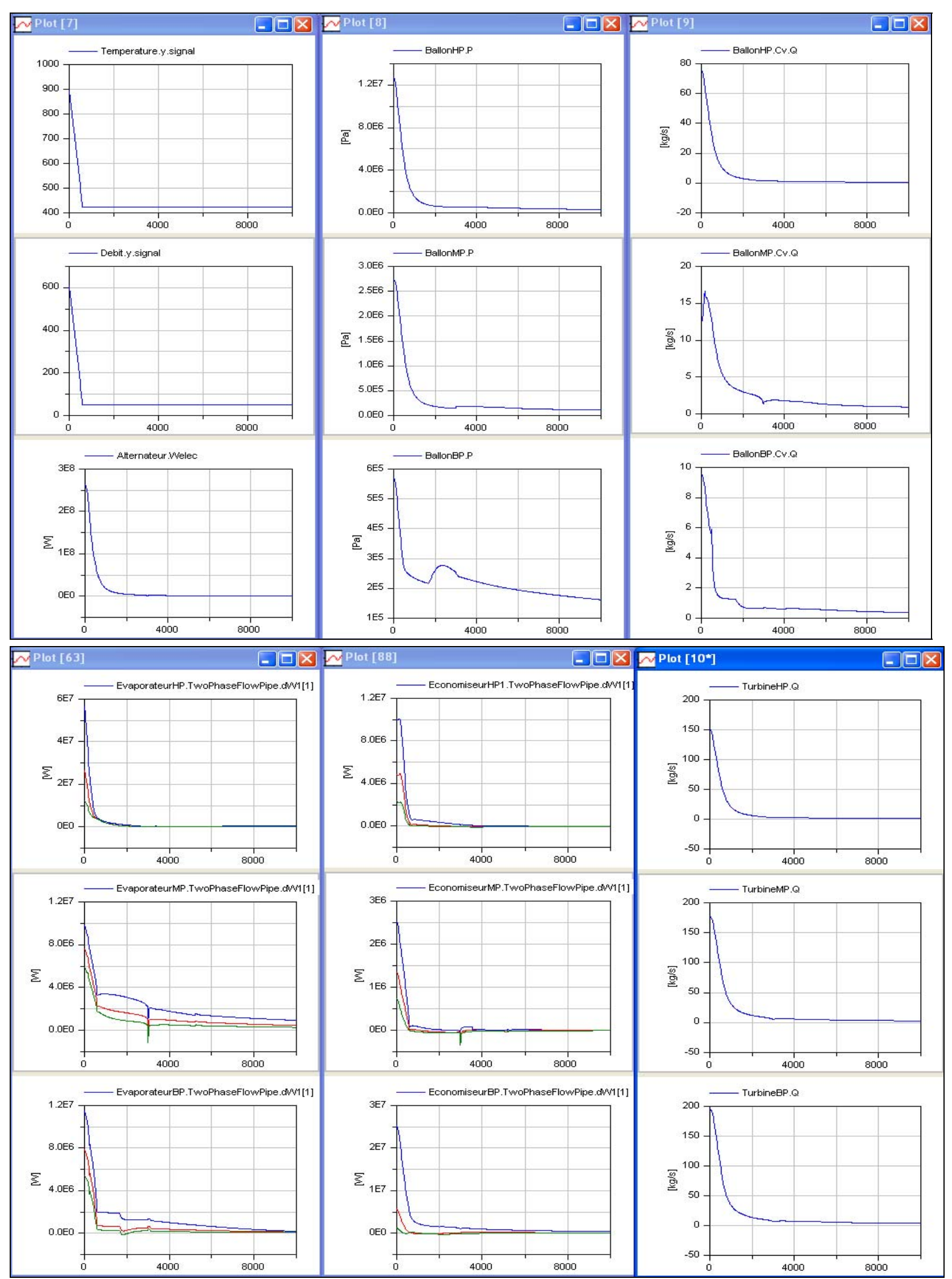

Figure 9: GT trip simulation 